\title{
Rammya Mathew: Improving referrals isn't about rationing care
}

\author{
Rammya Mathew GP \\ London
}

Frequently, a patient's opening gambit in a consultation is a request for a hospital referral. More often than not this turns out to be entirely appropriate, but occasionally I recommend an alternative course of action. My general impression is that patients don't mind this, as long as I've explained my rationale.

A handful of times, however, patients have asked whether my motive is to save money. I find this deeply upsetting-especially when the insinuation is that I stand to gain personally by declining their request.

However, I'm not surprised by such accusations when the media continue to portray GPs as fat cats and criticise any system level efforts to maintain efficiency in the NHS. I recently read a story in the Guardian about a supposedly controversial plan urging GPs to reduce hospital referrals. ${ }^{1}$ The article suggested that London GPs would be asked to stop sending acutely unwell patients to hospital. It's no wonder patients don't always trust that we're acting in their best interests when articles like this do the rounds.

The schemes referred to in the Guardian's article were not about rationing care for acutely unwell patients. They were about reviewing variation in outpatient referrals. Some practices within a mile's radius of each other, each with a very similar demographic, have a twofold difference in hospital referral rates. Doesn't this need to be explored?

I've been involved in facilitating one such referral optimisation scheme, from a quality improvement perspective. We've approached this by looking at referral data with practices and encouraging them to identify their own ideas for change. For example, some GPs weren't in the habit of using the advice and guidance portals (which can sometimes be used to get a clinical opinion from a specialist without making a referral) and so have chosen to try this as an alternative way of getting specialist input. Others realised that they hadn't been using certain community services and so are putting processes in place to help them use these more. Nothing about this is covert or underhand.

The bottom line is that GPs are not going to deny a patient referral on the basis of cost alone. This is unlike so many other parts of the world, where doctors are restrained by rigid insurance policies or their patients' savings. But, if we want to maintain a service that's free at the point of use, we have to keep the system as lean as possible, and this involves good gatekeeping.

In the meantime, GPs could do without the inflammatory headlines, which eat away at our patients' trust and make gatekeeping a whole lot more challenging than it needs to be.

Competing interests: I co-lead Islington GP Federation's Quality Improvement Team, who are currently working to deliver a locally commissioned referral optimisation scheme.

Provenance and peer review: Commissioned; not externally peer reviewed.

Taylor D. London GPs told to restrict specialist referrals under new NHS "rationing" plan Guardian 2019 Sep 8. https://www.theguardian.com/society/2019/sep/08/london-gps-toldto-restrict-specialist-referrals-under-new-nhs-rationing-plan.

Published by the BMJ Publishing Group Limited. For permission to use (where not already granted under a licence) please go to http://group.bmj.com/group/rights-licensing/ permissions 